\title{
Migrated surgical clip-induced choledocholithiasis
}
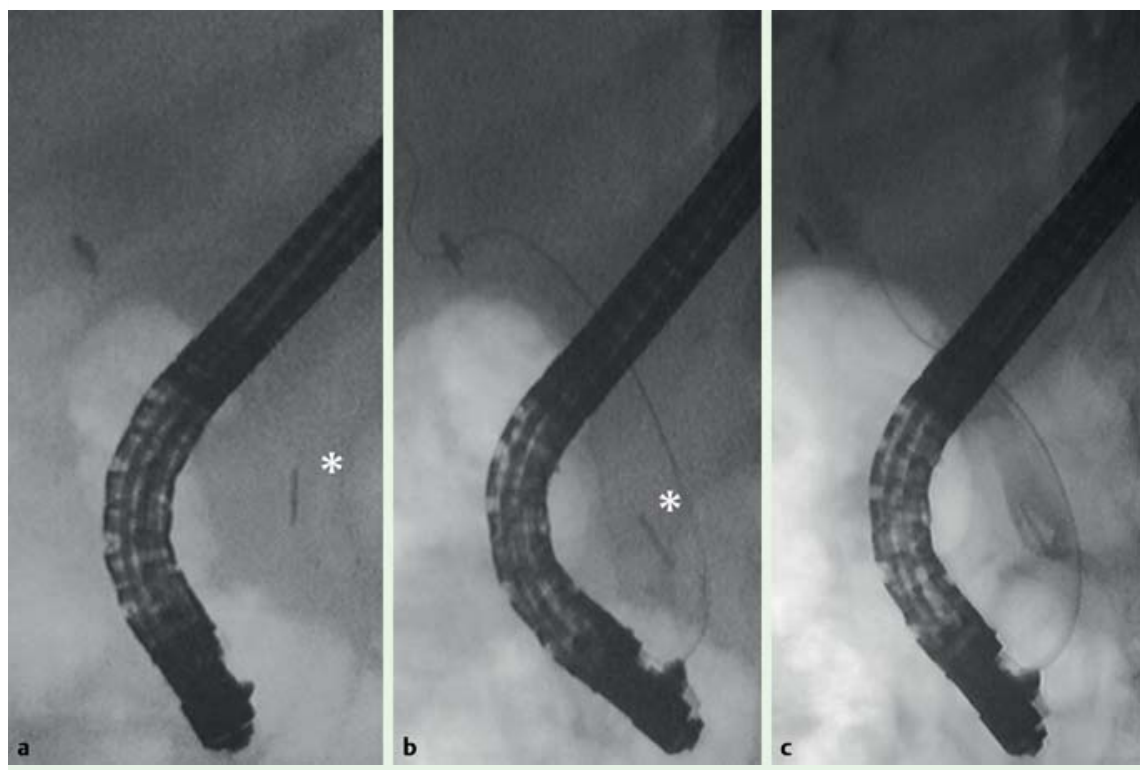

Fig. 1 Radiographic images during endoscopic retrograde cholangiopancreatography (ERCP). a, b Plain radiographs before contrast injection showing a mobile, metallic foreign body (asterisks), in addition to the cholecystectomy clip at the cystic duct. c Cholangiogram showing the metal clip located in a 10-mm oval-shaped defect suggestive of choledocholithiasis.
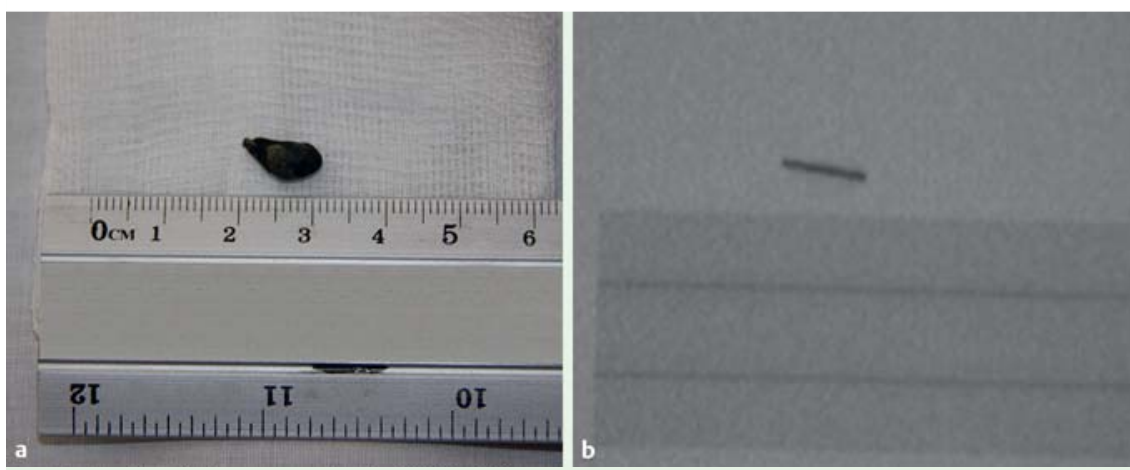

Fig. 3 Plain radiograph of the calculus (right) showing the metallic clip situated within the choledocholithiasis that it had induced.

An 88-year-old woman with a history of open cholecystectomy for symptomatic gallstones 12 years previously was admitted due to colicky right upper quadrant pain and obstructive jaundice. Abdominal ultrasonography showed extrahepatic bile duct dilatation $(12 \mathrm{~mm})$ and choledocholithiasis in the distal common bile duct (CBD). At endoscopic retrograde cholangiopancreatography (ERCP) before contrast injection, she was noted to have a mobile, metal foreign body inside the distal
CBD ( $\odot$ Fig. $1 \mathbf{a}, \mathbf{b}$ ), in addition to the cholecystectomy clip that was seen at the cystic duct. Cholangiogram revealed that this foreign body was located in the center of a 10 -mm oval-shaped defect that was suggestive of choledocholithiasis ( $\bullet$ Fig. 1 c). A sphincterotomy was performed, after which removal of a black calculus was achieved with a retrieval balloon, and a subsequent repeat cholangiogram was normal. On further examination, the calculus was found to have a metallic protu-

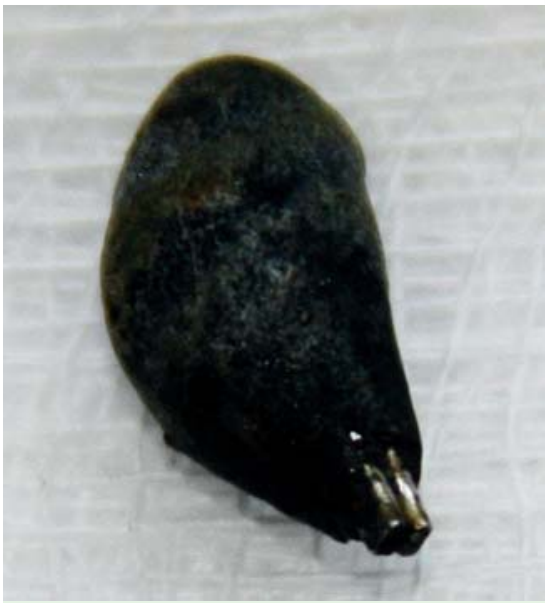

Fig. 2 The extracted 10-mm black calculus with a metallic protuberance at one end.

berance ( $\bullet$ Fig. 2). A plain radiograph of the calculus showed this to be the end of an embedded metal surgical clip ( $\bullet$ Fig. 3 ). The migration of a surgical cystic-duct clip into the CBD leading to stone formation was first described in 1978 and to date 80 cases have been reported [1]. Therefore, it remains a rarity in spite of the increasing number of laparoscopic cholecystectomies that are performed annually. Migration typically occurs at a median of 2 years post-cholecystectomy, albeit it has been described as much as 30 years after surgery $[1,2]$. The process of migration is likely to be influenced by inaccurate surgical clip placement, especially with short and/or wide cystic ducts [3], which results in bile duct injury, suppurative inflammation, and erosion of the clip through the bile duct into the lumen. Afterwards, the clip acts as the nidus for further calculus formation.

ERCP with sphincterotomy is the treatment of choice, although extraction using a balloon dilator and a rat-tooth forceps, in order to avoid papillotomy complications, has been recently reported [2].

\section{Endoscopy_UCTN_Code_CCL_1AZ_2AD}

Competing interests: None 
J. Molina-Infante, M. Fernandez-Bermejo, J. M. Mateos-Rodriguez Department of Gastroenterology, Hospital San Pedro de Alcantara, Caceres, Spain

\section{References}

1 Chong VH, Chong CF. Biliary complications secondary to post-cholecystectomy clip migration: a review of 69 cases. J Gastrointest Surg 2010; 14: 688-696

2 Munoz JC, Rascon-Aguilar I, Lambiase LR et al. Extraction of surgical clip-induced "lollipop" choledocholithiasis. Endoscopy 2010; 42 (Suppl 2): $15-16$

3 McMahon GS, Attar S, Dennison AR. Bile duct "clip-stones": why a stitch in time could save nine. Hepatogastroenterology 2010; 57: 1037-1039
Bibliography

DOI $10.1055 / \mathrm{s}-0030-1256844$

Endoscopy 2011; 43: E350 - E351

(c) Georg Thieme Verlag KG Stuttgart · New York . ISSN 0013-726X

\section{Corresponding author} J. Molina-Infante, MD

Unit of Gastroenterology

Hospital San Pedro de Alcantara

C/ Pablo Naranjo s/n

10003 Caceres

Spain

Fax: +34-927-621545

xavi_molina@hotmail.com 